\title{
Extravillus dividing fetal cells at CVS: evidence of their erythroblastic origin
}

\author{
G Terzoli, R Cartolano, F Rossella, A Cantù-Rajnoldi, B Brambati, M Fraccaro, \\ G Simoni
}

\begin{abstract}
Cytological and cytogenetic studies were performed on nucleated fetal cells present in chorionic villus transport medium. The erythroblastic origin of these cells was shown. Fetal erythroblasts in spontaneous mitosis were frequently observed; chromosome counts were obtained from them but poor quality often prevented banded analysis. Cytogenetic study of erythroblast metaphases can be useful as an additional diagnostic aid in cases of mosaicism with aneuploid cell lines.
\end{abstract}

(f Med Genet 1992;29:709-12)

The placenta is composed of trophoblast and a variety of other tissues of embryonic origin such as mesenchyme, endothelium, and blood. The space between the human placenta and the uterus contains an admixture of fetal and maternal cells and thus the syncytiotrophoblast is in direct contact with the maternal and fetal circulation at the same time. At histological examination nucleated fetal cells are commonly observed in the intervillus space and the passage of nucleated fetal cells to maternal blood has been documented. ${ }^{1-9}$ We investigated the presence of dividing fetal cells in the harvesting medium in which chorionic villi are transferred immediately after sampling. A preliminary study carried out on a small number of diagnostic CVS showed the presence of spontaneous metaphases floating in the harvesting fluid, and in those cases with a male fetus all these metaphases had a Y chromosome. These observations prompted us to perform a systematic study of harvesting fluid at CVS to investigate the consistency of this finding, characterise the type of spontaneous dividing cells, and evaluate the eventual diagnostic applications.

\section{Materials and methods}

Chorionic villi sampling was performed by transabdominal aspiration between 6.3 and 14.6 weeks of gestation. The aspirated material was transferred from the syringe to a $100 \mathrm{~mm}$ plastic Petri dish containing $10 \mathrm{ml}$ of RPM-I 1640 medium buffered with $25 \mathrm{mmol} / 1$ Hepes and supplemented with $10 \%$ fetal calf serum and antibiotics. Villi were isolated under an inverted microscope $(\times 100)$ and used for chromosome analysis. Complete removal of residual villus material was obtained by filtration through two layers of sterile nylon mesh gauze. After filtration, the harvesting fluid containing red blood cells and nucleated cells, singly or in small clusters, was checked for the presence of spontaneous metaphases. In each case, the harvesting fluid, containing enucleated erythrocytes and nucleated cells, was transferred into a sterile tube and centrifuged at $2000 \mathrm{rpm}$ for 10 minutes. The supernatant was discarded and the pellet resuspended and transferred into a $35 \mathrm{~mm}$ Petri dish containing $3 \mathrm{ml}$ of Chang medium with vinblastine sulphate at $0.01 \mu \mathrm{g} / \mathrm{ml}$ final concentration. The cell suspension was incubated overnight at $37^{\circ} \mathrm{C}$ in a humidified $5 \% \mathrm{CO}_{2}$ atmosphere.

\section{CYTOGENETIC ANALYSIS}

After incubation the cells were transferred to a tube, centrifuged, the supernatant discarded, and the pellet resuspended in $5 \mathrm{ml}$ of hypotonic solution (three parts $\mathrm{KCl} 0.05 \mathrm{~mol} / \mathrm{l}$ and one part trypsin EDTA $0.25 \%$ ) and maintained at $37^{\circ} \mathrm{C}$ for 20 minutes. Then $1 \mathrm{ml}$ of fixative (methanol:acetic acid 3:1) was added to the tube and the suspension immediately centrifuged. The pellet was resuspended in $5 \mathrm{ml}$ of methanol for five minutes, the cells centrifuged, and resuspended in $5 \mathrm{ml}$ of methanolacetic acid 3:1 fixative. This step was repeated twice. After centrifugation the cell pellet was dropped onto chilled wet slides and immediately put under a hot air flow to evaporate the fixative rapidly. This last step seems to be crucial for obtaining suitable chromosome spreads.

\section{CYTOLOGICAL STUDIES}

Six samples grossly contaminated with blood were used to evaluate cell morphology. After overnight incubation, nucleated cells were separated on a Ficoll-Hypaque density gradient and resuspended in $1 \mathrm{ml}$ of phosphate buffered saline (PBS) and bovine serum albumin (BSA). After a short precentrifugation (1500 rpm for 10 minutes) cytospins were prepared using a Shandon-Elliott cytocentrifuge (400 rpm for 10 minutes) and the slides stained with May-Grunwald-Giemsa. For intracytoplasmatic haemoglobin detection, the cytospins were fixed for 10 minutes in methyl alcohol, stained for five minutes with a solution of $2 \mathrm{ml}$ of $0.6 \%$ benzidine in $96 \%$ ethyl alcohol $70 \%+0.5 \mathrm{ml} \mathrm{H}_{2} \mathrm{O}_{2} 30 \mathrm{vol}$, and counterstained with Giemsa for 10 minutes. ${ }^{10}$

\section{Results}

CYTOLOGICAL OBSERVATIONS

In the six samples used for cytological evaluation, we found different types of nucleated
Received 4 January 1991 Revised version accepted 18 March 1992. 
cells, with the consistent presence of erythroblasts as indicated by their morphology and specific haemoglobin detection staining. We found 463 spontaneously dividing cells and all were positive for a haemoglobin cytoplasm (fig 1).

\section{CYTOGENETIC FINDINGS}

The presence of spontaneous extravillus metaphases was observed in 115 out of 129 samples of between 6.3 and 9.6 weeks' gestation and in 20 out of 42 samples of over 10 weeks' gestation. Seventy-six cases were $X Y$ and 58 cases $\mathrm{XX}$, while in one case a mixed XX/XY (38/ 112) cell population was observed.

From the pregnancies with a male fetal karyotype the presence of the $\mathrm{Y}$ chromosome was observed in all the 5999 metaphases scored. A total of 9866 metaphases was analysed in the 135 samples. The number of metaphases studied varied in each case, from two to more than 300 , but was over 10 metaphases in $82 \%$
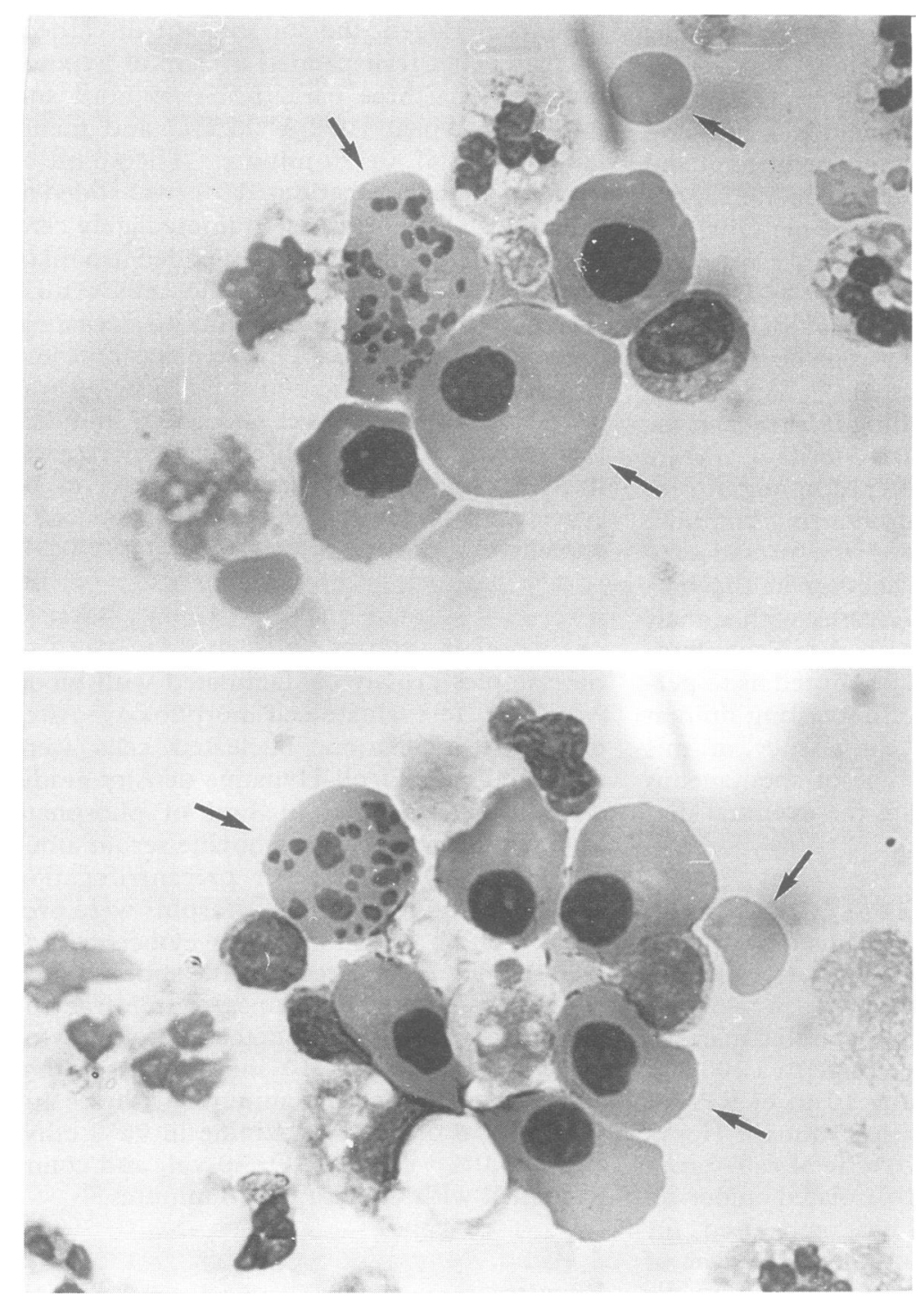

Figure 1 Cluster of nucleated cells found in the harvesting fluid at CVS. The arrows indicate erythrocytes and nucleated erythroblasts showing haemoglobin positivity as shown by benzidine staining. In each cluster one of the erythroblasts is spontaneously in mitosis. of the samples examined. The appearance of the chromosome morphology was not consistently satisfactory; in the majority of metaphases they were short and packed and unsuitable for banding (fig 2). However, chromosome counts were possible for all the cases with mitotic cells.

Cytogenetic results from these metaphases were compared with those observed by conventional analysis (direct method and long term culture) of chorionic villi samples for the corresponding cases. In the eight cases in which a uniformly abnormal karyotype had been found in villus cells the diagnosis was confirmed in the spontaneous extravillus metaphases. In two out of three cases with mosaicism in the villi the study of extravillus metaphases showed a normal chromosome complement, while in the remaining one the two metaphases observed confirmed the presence of trisomy 21 (table).

\section{Discussion}

Detection of extravillus spontaneous dividing cells in the harvesting medium in which chorionic villi are transferred immediately after CVS seems to be a common finding. Metaphases were detected in $89 \%$ of the samples from 6.3 to 9.6 weeks' gestational age, while at gestational ages over 10 weeks metaphases were present in only $47 \%$ of the samples studied.

Our results suggest that the relative proportion of cases with metaphases is higher at earlier stages of gestation and decreases with the progress of pregnancy. Among the 135 cases with dividing cells, the number of metaphases varied from two to more than 100 . In the majority of these cases more than 10 metaphases were observed. The presence of the $Y$ chromosome in 5999 metaphases derived from 76 pregnancies with a male fetus indicates the fetal origin of extravillus spontaneous dividing cells. In addition, our failure to detect dividing maternal cells in these specimens suggests that the risk of contamination with maternal metaphases is low.

We have no explanation for the case with a mixture of $\mathrm{XX}$ and $\mathrm{XY}$ cells, although the presence of a microinvasive myoma in this pregnancy could be a possible source of dividing maternal cells. However, the appearance of the XX metaphases with well spread and banded chromosomes was substantially different from that of the packed and poorly banded XY metaphases.

The specific haemoglobin staining of extravillus dividing cells indicated their erythroblastic nature (fig 1). This finding suggests that first trimester fetal erythroblasts can be used as an additional source of metaphases for prenatal cytogenetic study. At present, the quality of the metaphases is not satisfactory for banding analysis (fig 2). Thus, prenatal chromosome study of fetal erythroblasts cannot be considered an alternative to conventional karyotype analysis of chorionic villi by short term or long term cultures for two main reasons: the lack of spontaneous erythroblast metaphases in 


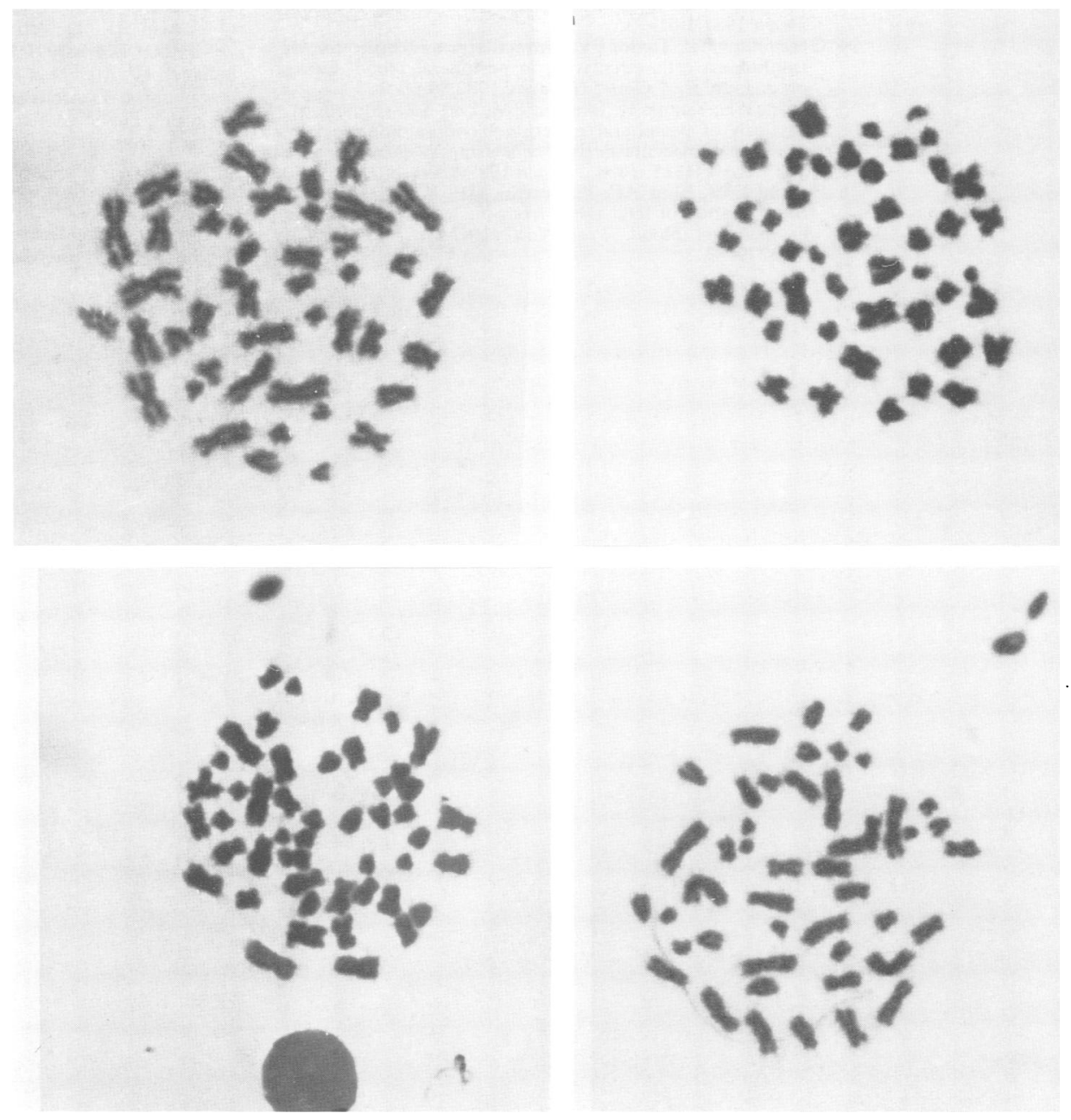

Figure 2 Appearance of erythroblast metaphases suitable for chromosome count.

several cases and the poor quality of the chromosomes. However, chromosome counts may be useful in cases of mosaicism or discrepancy when additional information is helpful for a correct diagnosis.

In seven cases out of the 135 with metaphases a non-mosaic aneuploid fetal karyotype was diagnosed by conventional analysis on chorionic villi. Chromosome counts of erythroblast spontaneous metaphases confirmed the aneuploid karyotype in all these cases. Furthermore, in three cases a mosaic condition with a trisomic cell line was observed in chorionic villi cells (table). In two of these, erythroblast metaphases showed a normal chromosome complement in agreement with the result

Comparison of cytogenetic results on erythroblast metaphases and chorionic villi cells in three cases of mosaicism.

\begin{tabular}{|c|c|c|c|c|}
\hline & \multicolumn{2}{|c|}{ Chorionic villi } & \multirow{2}{*}{$\begin{array}{l}\text { Erythroblast } \\
\text { metaphases }\end{array}$} & \multirow{2}{*}{$\begin{array}{l}\text { Amniocytes } \\
\text { (case 1) or } \\
\text { lymphocytes } \\
\text { at birth } \\
\text { (case 2) }\end{array}$} \\
\hline & $\begin{array}{l}\text { Direct } \\
\text { method }\end{array}$ & $\begin{array}{l}\text { Long term } \\
\text { culture }\end{array}$ & & \\
\hline Case 1 & $\underset{(12)}{46, X X / 47, X X X},+7$ & $\underset{(15)}{46, X X}$ & $\underset{(8)}{46, X X}$ & $\underset{(100)^{*}}{46, \mathrm{XX}}$ \\
\hline Case 2 & $46, \mathrm{XX} / 47, \mathrm{XXX}$ & $46, \mathrm{XX}$ & 46, XX & $46, \mathrm{XX}$ \\
\hline Case 3 & 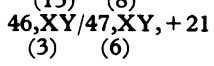 & $\begin{array}{c}46, X Y / 47, X Y,+21 \\
(8)(25)\end{array}$ & $47, \mathrm{XY},+21$ & $\begin{array}{c}\text { Not } \\
\text { analysed }\end{array}$ \\
\hline
\end{tabular}

( ) No of metaphases. * From 17 colonies of five cultures. of long term chorionic villi cultures. In the third one, in which a $46, \mathrm{XY} / 47, \mathrm{XY},+21$ mosaic condition had been found both in direct preparation and long term culture, the only two metaphases obtained from erythroblasts confirmed the presence of trisomy 21 . Unfortunately, the pregnancy ended in a spontaneous abortion and fetal tissues were not available for chromosome study.

In conclusion, we show that the dividing cells found in the harvesting medium at CVS are erythroblasts, and that a good number of them can be found in most cases. We did not succeed in obtaining metaphase spreads of high quality, but in several metaphases the chromosome number could be efficiently scored and this can be useful as an additional diagnostic aid in cases of mosaicism with aneuploid cell lines.

This study was supported by grants from ASM, Associazione Italiana Studio delle Malformazioni, Milano.

1 Schroder J, de la Chapelle A. Fetal lymphocytes in the maternal blood. Blood 1972;39:153-62.

2 Herzenberg LA, Bianchi DW, Schroder J, Cann HM, Herzenberg LA, Bianchi DW, Schroder J, Cann HM,
Iverson GM. Fetal cells in the blood of pregnant women: Iverson GM. Fetal cells in the blood of pregnant women:
detection and enrichment by fluorescence-activated cell detection and enrichment by fluorescence-activated
sorting. Proc Natl Acad Sci USA 1979;76:1453-5. 3 Iverson GM, Bianchi DW, Cann HM, Herzenberg LA. Iverson GM, Bianchi DW, Cann HM, Herzenberg LA.
Detection and isolation of fetal cells from maternal blood 
using the fluorescence-activated sorter (FACS). Prenat Diagn 1981;1:61-73.

4 Goodfellow CF, Taylor PV. Extraction and identification of trophoblast cells circulating in peripheral blood during
pregnancy. Br $₹$ Obstet Gynaecol 1982;89:65-8. pregnancy. Br $f$ Obstet Gynaecol 1982;89:65-8.

Ane AE, Kozma R, Johnson PM, Latt SA, Adinolfi $M$ Analysis of peripheral maternal blood samples for the presence of placenta-derived cells using Y-specific probes and McAb H315. Prenat Diagn 1988;8:591-607.

6 Bianchi DW, Flint AF, Pizzimenti MF, Knoll HM, Lat SA. Isolation of fetal DNA from nucleated erythrocytes in maternal blood. Proc Natl Acad Sci USA 1990 87:3279-83.
7 Yeoh SC, Sargent IL, Redman CWG, Wordsworth BP, Thein SL. Detection of fetal cells in maternal blood. Prenat Diagn 1991;11:117-23.

8 Bruch JF, Metezeau P, Garcia-Fonknechten N, et al. Trophoblast-like cells sorted from peripheral maternal blood using flow cytometry: a multiparametric study involving transmission electron microscopy and fetal DNA amplification. Prenat Diagn 1991;11:787-98.

9 Adinolfi $M$. On a non-invasive approach to prenatal diagnosis based on the detection of fetal nucleated cells in maternal blood samples. Prenat Diagn 1991;11:799-804. 10 Undritz E. Atlas of haematology. 2nd ed. Sandoz, 1973:28. 